\title{
Our work as health professionals: "With Great Power Comes Great Responsibility" [Stan Lee]
}

\author{
Robert A. deKemp, PhD, FASNC \\ a Cardiac Imaging, University of Ottawa Heart Institute, Ottawa, Canada
}

Received Jun 29, 2020; accepted Jun 29, 2020

doi: $10.1007 / \mathrm{s} 12350-020-02270-6$

The recent tragic events, including the police killings of George Floyd and Rayshard Brooks, have brought to light a second epidemic in the USA and indeed around the world-systemic racism. I must admit as an educated white man in Canada, I have struggled to appreciate the depth of racial bias and discrimination, and sadly underestimated their persistent consequences in our societies. In this difficult time, it is important that we acknowledge racism as a real problem, as some (but sadly not all) professional societies, journals and organizations in our field have already declared, e.g., the Society of Nuclear Medicine and Molecular Imaging, New England Journal of Medicine, Association of Black Cardiologists, among others. ${ }^{1-4}$ And while these declarations are a positive first step, they need to be followed with concrete actions to help address racial discrimination and the resulting inequities in quality-of-life and in healthcare that follow. Those of us in positions of influence have the greatest duty to provide active leadership and help effect these changes.

Eliminating racial bias is not only a social imperative but is also a scientific necessity if we are to progress in the development of personalized and precision medicine to improve health outcomes in our patients.

Health research is making some progress in the understanding of sex effects on the diagnosis and treatment of heart disease, due in part to the increased visibility and mandate of funding agencies to include 'sex and gender' effects in research study design, implementation, and reporting. ${ }^{5}$ So too should this mandate be expanded to include race, ethnicity, and social status, which are known to have profound effects on cardiovascular risk, but remain under-represented in many healthcare practices. ${ }^{6}$ Public health research and

\footnotetext{
Reprint requests: Robert A. deKemp, PhD, FASNC, Cardiac Imaging, University of Ottawa Heart Institute, Ottawa, Canada; radekemp@ottawaheart.ca

J Nucl Cardiol 2020;27:1087-8.

$1071-3581 / \$ 34.00$

Copyright (C) 2020 American Society of Nuclear Cardiology.
}

non-government organizations such as the Canadian Institutes for Health Research and the Heart and Stroke Foundation have created focused research programs for 'Gender and Health' and 'Indigenous Peoples' Health' representing particular historical problems of equity and diversity in the Canadian health system. These and similar programs also exist at the National Institutes of Health in the USA, ${ }^{7}$ and are needed in the healthcare and research systems around the world to "diagnose and treat' and eventually eliminate discrimination. ${ }^{2}$ Addressing racial bias in the health sciences, physical sciences, and (perhaps most importantly) in the social sciences are needed to inform public policy, that will inhibit all forms of discrimination, and promote equal access to health and wealth. ${ }^{8}$

A recent call for leadership by an actor the black community was answered by a young student in Florida asking him to deliver their High School graduation address. ${ }^{9}$ At the end of his video address, Dwayne Johnson declares "You're right here. Here you are." This epidemic will not end by re-educating those in power who hold racist beliefs, but rather by engaging the next generation of students and trainees who will be our future leaders. As leaders now, we can try to ensure that people from all walks of life have access to higher education and advanced positions in our training programs, with the goal that healthcare providers and decision makers will become more representative of the race and culture of the patients they are treating. A sobering statistic from the last Canadian census shows that while almost all high school students of color would like to get a higher degree, fewer than 2 out of 3 expect that they will actually achieve that goal (Fig. 1). Student outreach has been emphasized as a way to get young people engaged early in STEM and the health sciences. These programs have shown some success in attracting more women to these disciplines, but it is equally important to engage and provide continuing support to visible minority students so they have the opportunity to Represent and thrive in these careers. 
Black population Rest of the population

Think they will obtain a university degree

\section{$59.9 \%$}

\section{$78.8 \%$}

\section{Would like to obtain a university degree}

\section{$93.9 \%$}

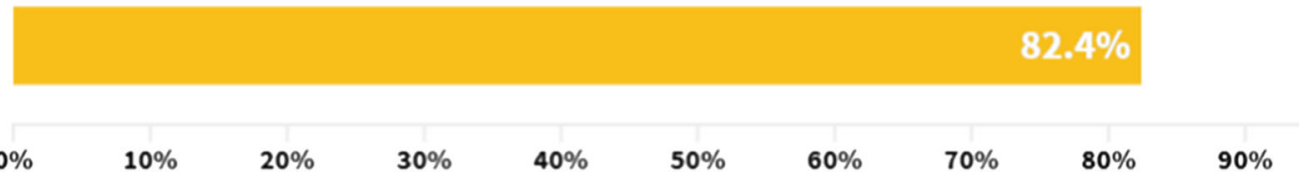

Figure 1. Expectations for higher education in Canada. Although 94 per cent of Black youth aged 15 to 25 said that they would like to get a bachelor's degree or higher, only 60 per cent thought that they actually could. Reproduced from CTVnews.ca report ${ }^{10}$.

Inaction is also providing implicit support and perpetuation of racist activities and practices. We must learn to identify and actively call out discrimination in our hospitals, training programs, workplaces, and communities. As the police events in Minneapolis showed us: to stand by idly and observe without acting is also a crime for those in positions of authority. We can each use our positions of influence and privilege to the fullest, and apply the Peter Parker Principle as health professionals, scientists, citizens, consumers, teachers, parents, and friends to enable real change towards true equity and diversity in our societies.

\section{Acknowledgements}

Thanks to Habibat Garuba in the Division of Cardiology for her thoughtful comments on diversity in our medical practice, and to my daughter Ella for enlightening discussions providing some perspectives of young professionals in training.

\section{Disclosure}

Robert A. deKemp receives royalties from PET imaging technologies licensed to Jubilant DraxImage and INVIA Medical Solutions.

\section{References}

1. SNMMI Statement on Racism in Healthcare. https://www.snmmi. org/NewsPublications/NewsDetail.aspx? ItemNumber $=33958$. Accessed 2 Jun 2020.
2. Evans MK, Rosenbaum L, Malina D, Morrissey S, Rubin EJ. Diagnosing and Treating Systemic Racism. N Engl J Med Editorial. https://www.nejm.org/doi/full/10.1056/NEJMe2021693. Accessed 10 June 2020.

3. Urgent Letter from Association of Black Cardiologists and Partners. $h$ ttps://abcardio.org/wp-content/uploads/2020/06/URGENT-Letter-fr om-ABC-and-Partners_May302020.pdf. Accessed 30 May 2020.

4. Promoting equity in health and in research. Canadian Institutes of Health Research: Message from the President. https://cihr-irsc.gc. ca/e/51994.html. Accessed 5 June 2020.

5. Science is better with sex and gender. Strategic Plan 2018-2023. Canadian Institutes of Health Research: Institute of Gender and Health. https://cihr-irsc.gc.ca/e/documents/igh_strategic_plan_201 8-2023-e.pdf

6. The "All of Us" Research Program. N Engl J Med. 15 August 2019; 381:668-676.

7. The Precision Medicine Initiative Cohort Program - Building a Research Foundation for 21st Century Medicine. Precision Medicine Initiative (PMI) Working Group Report to the Advisory Committee to the Director, NIH. https://www.nih.gov/sites/defa ult/files/research-training/initiatives/pmi/pmi-working-group-repo rt-20150917-2.pdf. Accessed 17 Sep 2015.

8. Vyas DA, Eisenstein LG, Jones DS. Hidden in plain sight-reconsidering the use of race correction in clinical algorithms. N Engl J Med. 2020. https://doi.org/10.1056/NEJMms2004740.

9. Jamie Samhan. etCanada.com. Dwayne Johnson Responds to High School Student Who Sent Him a Symbolic \$7. https://etcanada.c om/news/657173/dwayne-johnson-responds-to-high-school-stude nt-who-sent-him-a-symbolic-7/amp/. Accessed 15 Jun 2020.

10. Graham Slaughter. CTVnews.ca. Five charts that show what systemic racism looks like in Canada. https://www.ctvnews.ca/ca nada/five-charts-that-show-what-systemic-racism-looks-like-in-ca nada- 1.4970352

Publisher's Note Springer Nature remains neutral with regard to jurisdictional claims in published maps and institutional affiliations. 